\title{
Ventilatory limitations are not associated with dyspnea on exertion or reduced aerobic fitness in pectus excavatum: a critical information that must be highlighted to prevent inappropriate interventions.
}

\author{
Elise LUPON ${ }^{1}$, ALEXANDRE GASTON Lellouch $^{2}$, Benoit Chaput ${ }^{3}$, Curtis Cetrulo ${ }^{1}$, and \\ Jean Pierre Chavoin ${ }^{3}$ \\ ${ }^{1}$ Harvard Medical School \\ ${ }^{2}$ Hospital European George Pompidou \\ ${ }^{3}$ Paul Sabatier University - Rangueil Scientific Complex
}

July 4, 2021

\begin{abstract}
Cover letter Pediatric Pulmonology Dear Editor, Enclosed is a manuscript to be considered in Pediatric Pulmonology that does not require an abstract, usually. This letter to the editor entitled "Ventilatory limitations are not associated with dyspnea on exertion or reduced aerobic fitness in pectus excavatum: a critical information that must be highlighted to prevent inappropriate interventions" comments the reports by Hardie and al. which tested the hypothesis that PEX deformities are associated with a pulmonary impairment during exercise and concluded that resting lung volume measurements were associated with the anatomic degree of PEX severity.
\end{abstract}

\section{TITLE PAGE}

Ventilatory limitations are not associated with dyspnea on exertion or reduced aerobic fitness in pectus excavatum: a critical information that must be highlighted to prevent inappropriate interventions.

Elise Lupon (MD) 1,2, Alexandre G. LELLOUCH ${ }^{2,3}$ (MD, MSc), Benoit Chaput (MD, PhD $)^{1}$, Curtis L. Cetrulo Jr (MD, FAACS $)^{2,4}$, Jean-Pierre Chavoin $(M D, P h D)^{1}$

- 1,2 Lupon Elise, M.D: elupon@mgh.havard.edu

- $n^{\circ} 1$, First author, resident

- ${ }^{1}$ Department of Plastic surgery, University Toulouse III Paul Sabatier, Toulouse, France, 1 Avenue Jean Poulhès, TSA 5003231059 Toulouse cedex 9, France.

- ${ }^{2}$ Vascularized Composite Allotransplantation Laboratory, Center for Transplantation Sciences, Massachusetts General Hospital, Harvard Medical School, Boston, MA

- 2,3 Lellouch Gaston Alexandre, M.D, M.Sc.: alellouch@mgh.harvard.edu

- $\mathrm{n}^{\circ} 2$, Second author, Attending Plastic Surgeon

- ${ }^{2}$ Vascularized Composite Allotransplantation Laboratory, Center for Transplantation Sciences, Massachusetts General Hospital, Harvard Medical School, Boston, MA

- ${ }^{3}$ Department of Plastic Surgery, European George Pompidou Hospital, University of Paris, Paris, France 
- ${ }^{1}$ Chaput Benoit, M.D, PhD: benoitchaput31@gmail.com

- $\mathrm{n}^{\circ} 3$, Third author, professor

- ${ }^{1}$ Department of Plastic surgery, University Toulouse III Paul Sabatier, Toulouse, France

- 1 Avenue Jean Poulhès, TSA 5003231059 Toulouse cedex 9, France.

- ${ }^{2,4}$ CETRULO Curtis L. Jr, M.D, FAACS: CCETRULO@mgh.harvard.edu

- $\mathrm{n}^{\circ} 4$, Fourth author, Attending Plastic Surgeon

- ${ }^{2}$ Vascularized Composite Allotransplantation Laboratory, Center for Transplantation Sciences, Massachusetts General Hospital, Harvard Medical School, Boston, MA

- ${ }^{4}$ Department of Plastic Surgery, Massachusetts General Hospital, Boston, MA

- ${ }^{1}$ Chavoin Jean Pierre, MD, PhD: jean-pierre.chavoin@orange.fr

- $\mathrm{n}^{\circ} 5$, Fifth and last author, professor

- ${ }^{1}$ Department of Plastic surgery, University Toulouse III Paul Sabatier, Toulouse, France

- 1 Avenue Jean Poulhès, TSA 5003231059 Toulouse cedex 9, France

Key words: Custom-made silicone implant; Thoracic implants; Pectus excavatum, Ravitch surgery, Nuss surgery.

Corresponding author :

Elise LUPON

Plastic and reconstructive surgery

elupon@mgh.harvard.edu

Twitter handle of the corresponding Author: @Lupon7

List of authors:

Elise Lupon (MD, MSc)

Alexandre G. Lellouch (MD, MSc)

Benoit Chaput (MD, PhD)

Curtis L. Cetrulo (MD, FAACS)

Jean-Pierre Chavoin (MD, PhD)

The authors declare that there is no conflict of interest regarding the publication of this article.

No grants have been received for this article

Financial disclosure: no financial interest

Ventilatory limitations are not associated with dyspnea on exertion or reduced aerobic fitness in pectus excavatum: a critical information that must be highlighted to prevent inappropriate interventions.

Sir,

It was with great pleasure that we read the interesting article written by Dr. Hardie. and al. (1) and we would like to develop the impact of their findings on pectus excavatum (PEX) treatment with our experience. The authors tested the hypothesis that PEX deformities are associated with a pulmonary impairment during exercise and concluded that resting lung volume measurements were associated with the anatomic degree of PEX severity. However, respiratory limitations during maximal exercise are uncommon and PFT patterns have poor correlation with symptomatology or VO2.

We believe their conclusions could render invasive thoracic surgeries obsolete, as the functional requirements can no longer justify these risky operations. The results found by the authors also reinforce the 2019 NHS England conclusion (2) that there is not sufficient evidence to support the routine commissioning of thoracic 
surgical treatment for PEX. Indeed, many investigators suggest exercise intolerance in PEX is directly related to compromise in the cardiopulmonary response from the anatomic distortion of the chest wall. This justifies their aggressive treatment by Ravitch and Nuss procedure (3) and, therefore, accepting the possible life-threatening complications related (4).

Otherwise, the author's finding suggests that non-respiratory causes are more likely for the high rates of dyspnea and reduced aerobic fitness reported in PEX. A hypothesis to be explored could be the inadaptation to exercise related to the psychological impact induced by an erroneous health education given to patients with a PEX regarding the consequences of this one during exercise.

Finally, as PEX is a congenital deformity with psychological impact, we strongly advocate a procedure using silicone elastomer custom-made implant usable for life in order to fulfill aesthetic and psychological demands, with high-quality outcomes and very low morbidity (5). No serious statistics showing increased functional risk in the absence of bone remodeling have been reported so far, and none of the 638 patients perfomed by the senior author in the past 28 years have complained of actual or worsened cardiovascular problems.

\section{Reference}

1. William Hardie, Adam Powell, Todd Jenkins, et al. Ventilatory limitations are not associated with dyspnea on exertion or reduced aerobic fitness in pectus excavatum. Pediatric Pulmonology. January 24, 2021.

2. NHS England Commissioning Group. England specialized commissioning at National Health Service England. Surgery for pectus deformity (all ages). Available at: https://www.england.nhs.uk/publication/surgery-for-pectus-deformity-all- ages/. Accessed February 22, 2019.

3. Beiser GD, Epstein SE, Stampfer M, Goldstein RE, Noland SP, Levitsky S. Impairment of cardiac function in patients with pectus excavatum, with improvement after operative correction. $N$ Engl J Med .1972;287(6):267-272.

4. Hebra A, Kelly RE, Ferro MM, Yüksel M, Campos JRM, Nuss D. Life-threatening complications and mortality of minimally invasive pectus surgery. J Pediatr Surg . 2018 Apr;53(4):728-732.

5. Chavoin JP, Grolleau JL, Moreno B, Brunello J, André A, Dahan M, Garrido I, Chaput B. Correction of Pectus Excavatum by Custom-Made Silicone Implants: Contribution of Computer-Aided Design Reconstruction. A 20-Year Experience and 401 Cases. Plast Reconstr Surg. 2016 May;137(5):860e-871e. 